\title{
Hepatosomatic and Renosomatic Indices of Anabas testudineus Exposed to Various Levels of Cadmium
}

\author{
Sharifah Nadrah Syed Idrus, Mohd Riduan Abdullah, Fazlin Hazirah Mohd, \\ Mohd Sham Othman* ${ }^{\mathbb{D}}$
}

Center for Toxicology \& Health Risk Studies (CORE), Faculty of Health Sciences, Universiti Kebangsaan Malaysia, Kuala Lumpur, Malaysia

Email: *mso@ukm.edu.my

How to cite this paper: Idrus, S.N.S., Abdullah, M.R., Mohd, F.H. and Othman, M.S. (2022) Hepatosomatic and Renosomatic Indices of Anabas testudineus Exposed to Various Levels of Cadmium. Journal of Environmental Protection, 13, 161-170. https://doi.org/10.4236/jep.2022.131010

Received: December 7, 2021

Accepted: January 17, 2022

Published: January 20, 2022

Copyright $\odot 2022$ by author(s) and Scientific Research Publishing Inc. This work is licensed under the Creative Commons Attribution International License (CC BY 4.0).

http://creativecommons.org/licenses/by/4.0/

\begin{abstract}
Cadmium has a high level of toxicity and can have adverse health effects on living organisms including fish. This study is conducted to identify the effects of cadmium exposure on the Hepatosomatic Index (HSI) and Renosomatic Index (RSI) of Anabas testudineus. Anabas testudineus is exposed to four different cadmium treatment groups. The fishes were exposed to four treatment groups of different cadmium concentrations $(0.000 \mathrm{mg} / \mathrm{L}, 0.005 \mathrm{mg} / \mathrm{L}, 0.010$ $\mathrm{mg} / \mathrm{L}$ and $0.015 \mathrm{mg} / \mathrm{L}$ ) for 16 weeks. The results showed a decreasing trend of HSI value increasing cadmium concentration and exposure time. However, the opposite trend was observed with RSI where the higher the cadmium concentration over an increased exposure time, the higher the RSI. In conclusion, the study outcome shows significant changes in the value of HSI and RSI between different treatment groups with exposure time.
\end{abstract}

\section{Keywords}

Cadmium, Anabas testudineus, Hepatosomatic Index, Renosomatic Index

\section{Introduction}

The advancement in science and technology is moving in tandem with the development of industrial activities worldwide. Heavy metal pollution has become a global concern and is no longer a foreign issue. According to [1], the loss of 1.6 million children's lives is due to the contamination of drinking water sources which has led to heavy metal poisoning. The occurrence of heavy metal pollution is no longer foreign in Malaysia. Excessive urbanization and industrial ac- 
tivities are the main factors that result in pollution of the Selangor River [2]. Heavy metals can be defined as elements where the density is more than $5 \mathrm{~g} \mathrm{~cm}^{3}$ and subsequently classified as inorganic chemical hazards [3]. According [4], the usage of heavy metals such as mercury, lead, arsenic and cadmium is diverse in industrial and agricultural activities which in turn has the potential to be a threat to human health.

Cadmium is chosen for this study due to its natural properties which in turn can cause a negative impact on living organisms in general. Cadmium has been classified as a Group 1 heavy metal which is a human carcinogen [5]. Moreover, cadmium can be introduced to the environment naturally and via human activities. For natural resources according to [6], the consumption of food contaminated with cadmium such as leafy vegetables, meat organs, crustaceans and contaminated water can cause adverse health implications to organisms in the long run. However, anthropogenic activity is the main source of human cadmium exposure such as zinc and lead fusion, tin, sealing plans, battery production processes, plating processes and even tobacco use [7].

Exposure of cadmium to living organisms can cause detrimental toxic effects. The study by [8] has conceptualized that colorectal cancer may occur due to the ingestion of toxic trace elements such as cadmium. Exposure to cadmium results in inflammation, damage to vascular endothelium as well as reproductive cells [7]. In fact, based on the same study [7], the prevalence of bone mineralization, osteomalasia and osteoporosis is due to the replacement of calcium $(\mathrm{Ca})$ ions by cadmium in the bones. A study by [4] has reported that fish has the ability to accumulate heavy metals in its body tissues. Therefore, information on ingested fish species as well as the level of heavy metal content incorporated in them is useful in reducing the danger to public health [4]. The accumulation of heavy metals in humans may occur as the result of the ingestion of fish contaminated with heavy metals in the long run [9].

In this study, gravimetric indices are used to identify the effects of cadmium exposure on A. testudineus which consists of Hepatosomatic Index (HSI) and Renosomatic Index (RSI) in different concentrations of cadmium over time exposure of 16 weeks The study conducted by [10] conceptualizes that the gravimetric analysis is applied for the identification of the status change of each organ tested for the purpose of the study. Anabas testudineus or also known as the climbing perch has been selected as a biological indicator for the effects of cadmium exposure in different cadmium concentration groups with time exposure. According to a study by [11] [12] [13] as cited by [14], the climbing perch is a native species at which has high endurance against the harsh environment which includes hypoxia, environments where the salinity is high, low $\mathrm{pH}$ and to contaminants as well.

\section{Materials and Methods}

This study is an experimental study utilizing a random and experimental study 
design. Anabas testudineus fingerlings were acclimatized to laboratory conditions for three days in dechlorinated tap water prior to any treatment. The fingerlings were then divided into four treatment groups of different exposure to cadmium concentrations; $0 \mathrm{mg} / \mathrm{L}$ (control), $0.005 \mathrm{mg} / \mathrm{L}$ (low exposure), 0.010 $\mathrm{mg} / \mathrm{L}$ (medium exposure) and $0.015 \mathrm{mg} / \mathrm{L}$ (high exposure) for 16 weeks. To ensure survival of the fish fry are maintained at $89 \%$ [15], the stocking density of the fish fry will be at 4 fish per liter of water [16]. The fingerlings were given commercial fish pallets ad libitum once daily until satiety with the total for each feed did not exceed the recommended feeding rate of 5\% from the body weight [17]. To the farmed fish for the feeding purpose, excess leftover feed was removed after feeding and water-change were carried out every fortnight to ensure the water quality is suitable for fish to survive and grow without affecting the intended cadmium exposure conditions.

Twenty individuals were sampled every 4 weeks and sacrificed by ice water euthanasia. The samples were pat-dried before their total body weight was measured. They are then autopsied to extract their livers and kidneys. All organs were weighed and the respected indices were determined by the ratio of the organ to body weight. The gravimetric index can be determined by calculating the HSI and RSI of A. testudineus. According to [18], the formula used to determine each parameter is as in Figure 1.

One-Way ANOVA test was used to identify the effect of cadmium exposure on the HSI and RSI of A. testudineus in different cadmium treatment groups. Two-Way ANOVA test was used to compare different concentrations of cadmium for the gravimetric index of A. testudineus with time exposure.

\section{Results and Discussion}

\subsection{Hepatosomatic Index (HSI)}

Figure 2 showed the average Hepatosomatic Index (HSI) of A. testudineus in different treatment groups of cadmium. Based on the results, the low exposure group had the lowest HSI value of $1.55 \% \pm 0.21 \%$ followed by the high exposure group $(1.57 \% \pm 0.25 \%)$ and medium exposure group $(1.58 \% \pm 0.23 \%)$. The control group has the highest HSI value of $1.92 \% \pm 0.46 \%$. One-way ANOVA test is performed for the HSI of $A$. testudineus after the overall data distribution for HSI is normally distributed. Test result has found that there are significant differences for the four treatment groups tested for the HSI of $A$. testudineus $(\mathrm{p}<$ $0.05)$.

Organ Weight of Individual

$$
\text { Specific Index Calculated }=\frac{\text { Fish }(\mathrm{g})}{\text { Body Weight of Indivisual }} \times 100 \%
$$

Fish $(\mathrm{g})$

Figure 1. Formula for gravimetric Indices. Source: Sadekarpawar and Parikh [18]. 


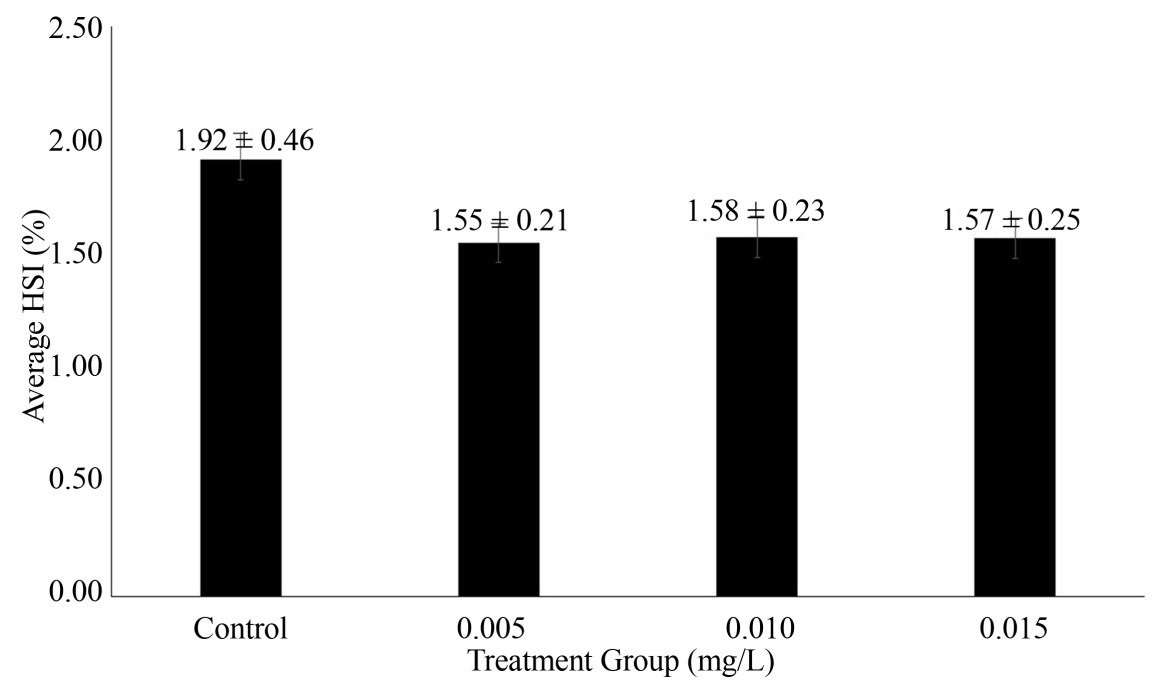

Figure 2. The average hepatosomatic index (HSI) (\%) in different treatment groups.

Figure 3 shows the average HSI of $A$. testudineus in different treatment groups, according to the time exposure of 16 weeks. In week 4 , the control group has recorded an average HSI value of $2.59 \% \pm 0.78 \%$ followed by the medium exposure group $(1.93 \% \pm 0.41 \%)$, low exposure group $(1.86 \% \pm 0.47 \%)$ and the high exposure group $(1.91 \% \pm 0.64 \%)$. At week 8 , it is found that the low exposure group has the lowest average HSI value of $1.40 \% \pm 0.47 \%$ followed by medium exposure group $(1.44 \% \pm 0.31 \%)$. The control group exhibits the highest average HSI value of $1.57 \% \pm 0.20 \%$ while the high exposure group demonstrates the second highest HSI average value of $1.49 \% \pm 0.59 \%$.

Based on the observation in the twelfth week, the control group has recorded the highest average HSI value of $1.68 \% \pm 0.22 \%$ followed by the medium exposure group $(1.63 \% \pm 0.29 \%)$. The low exposure group showed the lowest average HSI value $(1.50 \% \pm 0.20 \%)$ followed by the high exposure group $(1.57 \% \pm$ $0.23 \%$ ). During the final week, the highest average HSI value was recorded by control group, followed by the low, high and medium exposure groups $(1.82 \% \pm$ $0.43 \% ; 1.45 \% \pm 0.38 \% ; 1.31 \% \pm 0.23 \% ; 1.30 \% \pm 0.51 \%)$.

Based on the normal distribution of data for the HSI, the Two-Way ANOVA test is conducted. The test result has found that there is a significant difference $(\mathrm{p}<0.05)$ in different treatment groups for the HSI value with time exposure.

Figure 2 exhibits that the control group has the highest mean value of HSI. The $0.005 \mathrm{mg} / \mathrm{L}$ followed by the $0.015 \mathrm{mg} / \mathrm{L}$ have the lowest mean value of HSI. According to [19], the effect of metals and the excessive usage of energy reserves result in the development of stress condition as the result of the increase in its demand which also may result in the reduction of HSI value from the exposure to cadmium. The lowest mean of HSI value is the $0.005 \mathrm{mg} / \mathrm{L}$ group from the comparison between treatment groups in Figure 2 which may be the result of the induction of oxidative stress and DNA damage in the liver as stated in the study conducted by [20] on the Cyprinus carpio species due to the exposure to a low concentration of cadmium $(<1 \mathrm{mg} / \mathrm{L})$. 


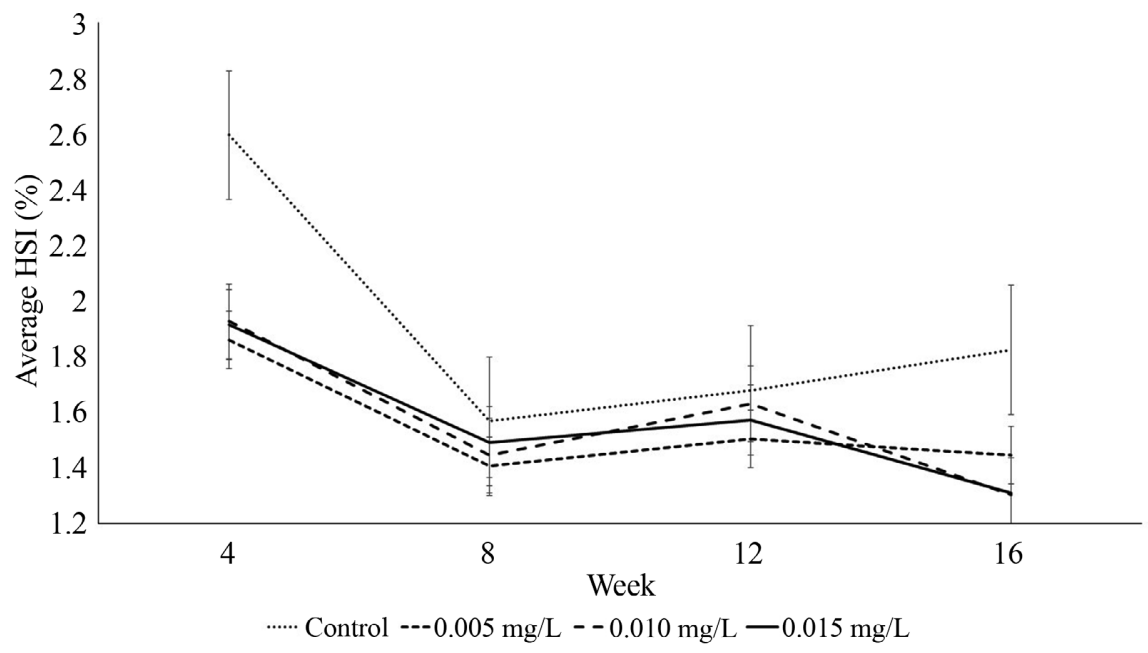

Figure 3. The comparison of average hepatosomatic index (HSI) (\%) of each treatment group with time exposure.

Figure 3 reported an overall decreasing trend of the HSI values for all groups from Week 4 to Week 16, being that the $0.010 \mathrm{mg} / \mathrm{L}$ has the lowest HSI value, followed by the $0.015 \mathrm{mg} / \mathrm{L}$ group. The study of [18] suggests that the most affected tissue by the toxicant via blood circulation entry is the liver as the detoxification process occurs in the particular tissue. [21] also conceptualizes that the production of toxic actions on several crucial physiological processes may occur as the result of the metal accumulation in the hematopoietic organs such as liver. It is reported by [22] that the tissue that acts as the main storage of heavy metals is the liver while the lowest levels of metals analysed are found in gonad. It must be noted that there was a small increase in HSI between week 8 and 12. While the change is not significant, we postulated that this was the result of the homeostasis process employed by the internal system of the fish. Upon exposure to heavy metal, the body would start to produce metallothionein to counter the effect of Cadmium, hence the increase in HSI. However, after prolonged exposure to cadmium, this homeostatic balance could no longer cope with the accumulation of cadmium which resulted in the decrease of HSI from week 12 onwards.

The study by [23] has reported the reduction in HSI value of Cyprinus carpio and Perca fluviatilis treated in cadmium. The study by [24] suggests that the decrease of the HSI value from the exposure to pollutants may be the result of stress factors and limitations of food. The highest mean value of the HSI belongs to the control group with time exposure which is parallel to the study by [24] as the HSI value of the A. testudineus in the control group is higher than the heavy metal-intoxicated group. The continuous exposure to toxicants may trigger fibrosis as the result of the loss of regeneration ability of cells at which may result in the cirrhosis of liver and eventually liver failure given that all liver parts have been affected by fibrosis [23]. The alteration of many biochemical parameters which may result in the liver damage may be the result of the higher accumulation of heavy metal in the liver, according to [25]. [26] has reported that the liver 
damage occurrence as the result of pollution may leads to the decrease in HSI value.

\subsection{Renosomatic Index (RSI)}

Figure 4 shows the average Renosomatic Index (RSI) for each exposure groups. The RSI value of the medium exposure group was the highest $(1.73 \% \pm 0.21 \%)$ followed by the high and low exposure groups $(1.65 \% \pm 0.23 \%$ and $1.65 \% \pm$ $0.15 \%$ respectively). The control group has the lowest RSI value of $1.24 \% \pm$ $0.42 \%$. Based on the normal data distribution for the RSI, the One-Way ANOVA test is performed. The result of this test has recorded that there is a significant difference $(\mathrm{p}<0.05)$ between the four treatment groups tested for RSI.

Figure 5 records the average RSI for each treatment group according to the change in time. At week 4, the highest average RSI value is from the low exposure group $(1.66 \% \pm 0.41 \%)$ followed by the medium exposure group $(1.46 \% \pm$

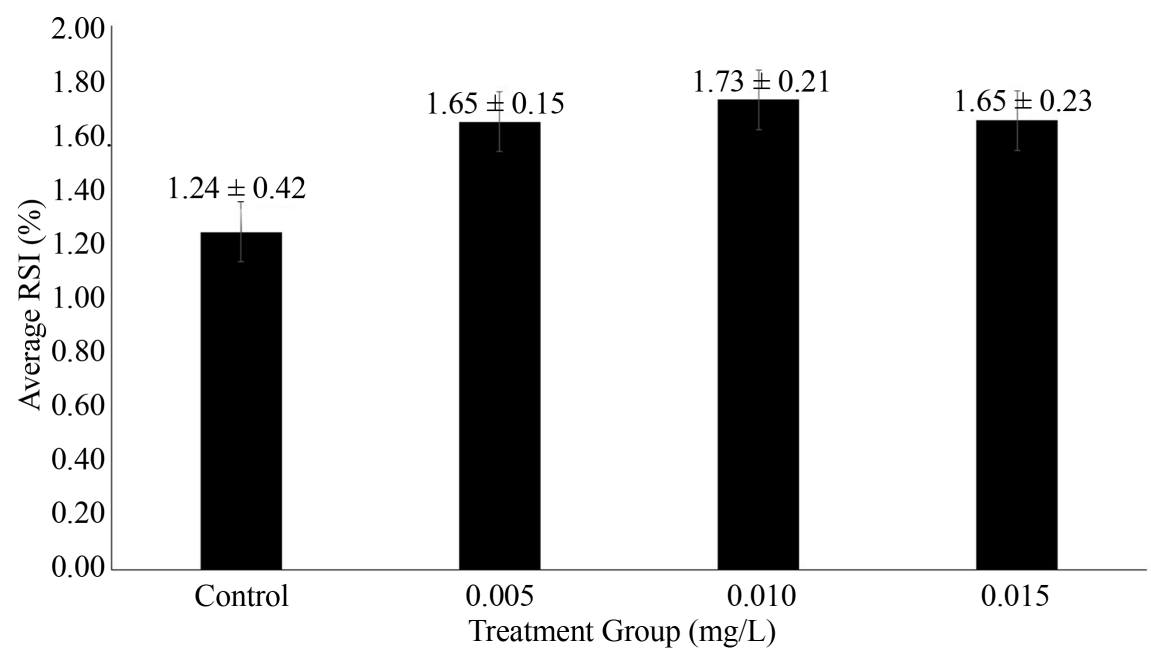

Figure 4. The average renosomatic index (RSI) (\%) in different treatment groups.

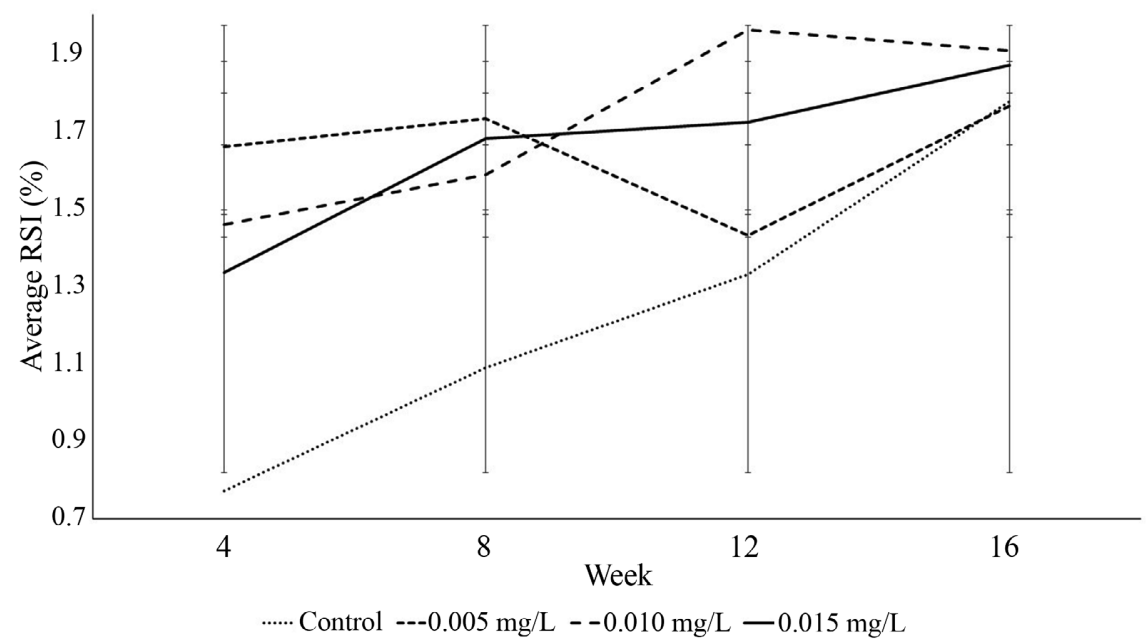

Figure 5. The comparison of average rensosomatic index (RSI) (\%) of each treatment group with time exposure. 
$0.77 \%$ ). The lowest value for RSI is $0.77 \% \pm 0.37 \%$ (control group) followed by the high exposure group which is $1.33 \% \pm 0.53 \%$. In the eighth week, the low exposure group has the highest mean RSI value of $1.73 \% \pm 0.49 \%$ while the control group shows the lowest RSI value of $1.09 \% \pm 0.64 \%$. The high exposure group has the second highest RSI value of $1.68 \% \pm 0.42 \%$ followed by the medium exposure group of $1.59 \% \pm 0.29 \%$.

The twelfth week trend for RSI showed that the medium exposure group has the highest average RSI value of $1.96 \% \pm 0.15 \%$ followed by the high exposure group of $1.72 \% \pm 0.23 \%$. The control group shows the lowest average RSI value of $1.33 \% \pm 0.38 \%$ followed by the low exposure group of $1.43 \% \pm 0.27 \%$. In the final week, the highest RSI average value is $1.91 \% \pm 0.30 \%$ which is the medium exposure group followed by the high exposure group which is $1.87 \% \pm 0.49 \%$. The low exposure group demonstrates the lowest RSI value of $1.77 \% \pm 0.30 \%$ followed by the control group of $1.78 \% \pm 0.31 \%$.

The Two-Way ANOVA test is performed for the RSI after it is found that the overall distribution of data for the RSI of A. testudineus is normal. This test has noted that there is a significant difference for the four treatment groups of the RSI with time exposure $(\mathrm{p}<0.05)$.

The increase in RSI values may be due to the formation of stones in the fish kidney, along with the disturbances of the calcium metabolism and the occurrence of hypercalciuria in the kidney [27]. According to the same study, this is also due to the fact that the maximum accumulation of cadmium concentration in fish occurs in the kidney, indicating that kidney plays an active role in handling cadmium as compared to spleen [28]. The same source has also reported that the immunosuppressed effects that are caused by cadmium in the kidney include the down-regulation of the pro-inflammatory and anti-inflammatory cytokine genes in the kidney of $P$. fulvidraco that are exposed to high dose of cadmium.

The study conducted by [29] has reported that the glomerular edema and necrosis plus the disorganization of renal tubules occur as the result of the cadmium exposure to Tilapia mossambica for 20 days. According to [30], the shrinkage of renal corpuscle, pyknotic nuclei, the increase of the diameter of renal tubules, the expansion and necrosis of glomerulus, vacuolation and the Bowman's Space dilation are reported from the kidney tissue of $\mathrm{P}$. hypothalmus exposure to different concentrations of a heavy metal. From the study, it can be indicated that physical changes of fish kidney occur as the result of exposure to heavy metal.

\section{Conclusion}

This study found that HSI shows a decreasing trend according to cadmium exposure concentration and exposure duration. An increase in cadmium concentration would lead to a decrease in HSI. Similar trend is also observed when exposure duration is compared. An opposite trend, however is observed with RSI. 
With an increase in cadmium exposure concentration, RSI is found to increase. An increase in exposure duration also shows a similar trend. In conclusion, both exposure concentration and exposure duration affect the gravimetric indices studied. We suggest that in future studies, a longer study duration should be employed so that the trend in HSI and RSI could be observed better.

\section{Acknowledgements}

This research was conducted with supplies and laboratories provided by Environmental Health \& Industrial Safety Program and the Center for Toxicology \& Health Risk Studies (CORE), Faculty of Health Sciences, Universiti Kebangsaan Malaysia. Research ethics for this study was approved by UKM Animal Ethics Committee (Approval No.: FSK/2020/MOHD SHAM/25-NOV./1137-DEC.-2020DEC.-2021).

\section{Conflicts of Interest}

The authors whose names are listed immediately below certify that they have no affiliations with or involvement in any organization or entity with any financial interest or non-financial interest in the subject matter or materials discussed in this manuscript.

\section{References}

[1] Fernández-Luqueño, F., López-Valdez, F., Gamero-Melo, P., Luna-Suárez, S., Aguilera-González, E., Martínez, A., García-Guillermo, M., et al. (2013) Heavy Metal Pollution in Drinking Water-A Global Risk for Human Health: A Review. African Journal of Environmental Science and Technology, 7, 567-584.

[2] Othman, F., Chowdhury, M.S.U., Wan Jaafar, W.Z., Faresh, E.M.M. and Shirazi, S.M. (2018) Assessing Risk and Sources of Heavy Metals in a Tropical River Basin: A Case Study of the Selangor River, Malaysia. Polish Journal of Environmental Studies, 27, 1659-1671. https://doi.org/10.15244/pjoes/76309

[3] Kumar, M., Gogoi, A., Kumari, D., Borah, R., Das, P., Mazumder, P. and Tyagi, V.K. (2017) Review of Perspective, Problems, Challenges, and Future Scenario of Metal Contamination in the Urban Environment. Journal of Hazardous, Toxic, and Radioactive Waste, 21, 1-16. https://doi.org/10.1061/(ASCE)HZ.2153-5515.0000351

[4] Annabi, A., Said, K. and Messaoudi, I. (2013) Cadmium: Bioaccumulation, Histopathology and Detoxifying Mechanisms in Fish. American Journal of Research Communication, 1, 60-79.

[5] International Agency for Research on Cancer (2012) IARC Monographs on the Evaluation of Carcinogenic Risks to Humans, Volume 100c: Cadmium and Cadmium Compounds. IARC, Lyon.

[6] Bernhoft, R.A. (2013) Cadmium Toxicity and Treatment. The Scientific World Journal, 2013, Article ID: 394652. https://doi.org/10.1155/2013/394652

[7] Słojewska, A. and Gutowska, I. (2019) Contamination of Food with Cadmium and Dioxins-Influence on the Human Body. Pomeranian Journal of Life Sciences, 65, 110-116. https://doi.org/10.21164/pomjlifesci.598

[8] Emre, O., Demir, H., Dogan, E., Gonullu, E., Turan, N., et al. (2013) Plasma Con- 
centrations of Some Trace Element and Heavy Metals in Patients with Metastatic Colon Cancer. Journal of Cancer Therapy, 4, 1085-1090.

https://doi.org/10.4236/jct.2013.46124

[9] Ahmed, M.K., Baki, M.A., Islam, M.S., Kundu, G.K., Habibullah-Al-Mamun, M., Sarkar, S.K. and Hossain, M.M. (2015) Human Health Risk Assessment of Heavy Metals in Tropical Fish and Shellfish Collected from the River Buriganga, Bangladesh. Environmental Science and Pollution Research, 22, 15880-15890. https://doi.org/10.1007/s11356-015-4813-Z

[10] Thammachoti, P., Khonsue, W., Kitana, J., Varanusupakul, P. and Kitana, N. (2013) Morphometric and Gravimetric Parameters of the Rice Frog Fejervarya limnocharis Living in Areas with Different Agricultural Activity. Journal of Environmental Protection, 3, 1403-1408. https://doi.org/10.4236/jep.2012.310159

[11] Chew, S.F. and Ip, Y.K. (2014) Excretory Nitrogen Metabolism and Defence against Ammonia Toxicity in Air-Breathing Fishes. Journal of Fish Biology, 84, 603-638. https://doi.org/10.1111/jfb.12279

[12] Davenport, J. and Abdul Matin, A.K.M. (1990) Terrestrial Locomotion in the Climbing Perch, Anabas testudineus (Bloch) (Anabantidea, Pisces). Journal of Fish Biology, 37, 175-184. https://doi.org/10.1111/j.1095-8649.1990.tb05938.x

[13] Klepper, O., Chairuddin, G.T., Iriansyah and Rijksen, H.D. (1992) Water Quality and the Distribution of Some Fishes in an Area of Acid Sulphate Soils, Kalimantan, Indonesia. Hydrobiology Bulletin, 25, 217-224. https://doi.org/10.1007/BF02270806

[14] Zhang, W.L., Xie, H.Q., Zou, X.H., Li, J., Xu, L., Li, Y.P., Zhou Z.G., Jin, T., Ma, D. and Zhao, B. (2019) The Toxic Effects of in Situ Exposure of a Native Fish Species (Anabas testudineus) to Electronic Waste Pollution. Science of the Total Environment, 690, 1170-1177. https://doi.org/10.1016/j.scitotenv.2019.06.479

[15] Anantharaja, K., Mohapatra, B., Pillai, B. and Kumar, R. (2017) Growth and Survival of Climbing Perch, Anabas testudineus in Nutrient Film Technique (NFT) Aquaponics System. International Journal of Fisheries and Aquatic Studies, 5, 24-29.

[16] Zaaim, Z., Christianus, A. and Ismail, M.F.S. (2018) Effect of Stocking Density and Salinity on the Growth and Survival of Golden Anabas Fry. Journal of Survey in Fisheries Sciences, 4, 26-37. https://doi.org/10.18331/SFS2018.4.2.3

[17] Akbar, J., Mangalik, A. and Fran, S. (2016) Application of Fermented Aquatic Weeds in Formulated Diet of Climbing Perch (Anabas testudineus). International Journal of Engineering Research and Science, 2, 240-243.

[18] Sadekarpawar, S. and Parikh, P. (2013) Gonadosomatic and Hepatosomatic Indices of Freshwater Fish Oreochromis mossambicus in Response to a Plant Nutrient. World Journal of Zoology, 8, 110-118.

[19] Çiftçi, N., Ay, Ö., Karayakar, F., Cicik, B. and Erdem, C. (2015) Effects of Zinc and Cadmium on Condition Factor, Hepatosomatic and Gonadosomatic Index of Oreochromis niloticus. Fresenius Environmental Bulletin, 24, 3871-3874.

[20] Jia, X.Y., Zhang, H.J. and Liu, X.X. (2011) Low Levels of Cadmium Exposure Induce DNA Damage and Oxidative Stress in the Liver of Oujiang Colored Common Carp Cyprinus carpio var. color. Fish Physiology and Biochemistry, 37, 97-103. https://doi.org/10.1007/s10695-010-9416-5

[21] Kondera, E., Ługowska, K. and Sarnowski P. (2014) High Affinity of Cadmium and Copper to Head Kidney of Common Carp (Cyprinus carpio L.). Fish Physiology and Biochemistry, 40, 9-22. https://doi.org/10.1007/s10695-013-9819-1

[22] Begum, A., Mustafa, A.I., Amin, M.N., Chowdhury, T.R., Quraishi, S.B. and Banu, N. (2013) Levels of Heavy Metals in Tissues of Shingi Fish (Heteropneustes fossilis) 
from Buriganga River, Bangladesh. Environmental Monitoring and Assessment, 185, 5461-5469. https://doi.org/10.1007/s10661-012-2959-4

[23] Dewi, N.K. and Prabowo, R. (2017) Determination of Liver Somatic Index (LSI) and Gonadosomatic Index (GSI) Value of Carp (Cyprinus carpio) and Nile tilapia (Perca fluviatilis). International Journal of Scientific and Research Publications, 7, 220-223.

[24] Pandit, D.N., Priyanka and Gupta, M.L. (2019) Hepato-Somatic Index, Gonado-Somatic Index and Condition Factor of Anabas testudineus as Bio-Monitoring Tools of Nickel and Chromium Toxicity. International Journal of Innovations in Engineering and Technology, 12, 25-28.

[25] Abdel-Warith, A.A., Younis, E.M., Al-Asgah, N.A. and Wahbi, O.M. (2011) Effect of Zinc Toxicity on Liver Histology of Nile tilapia, Oreochromis niloticus. Scientific Research and Essays, 6, 3760-3769. https://doi.org/10.5897/SRE11.883

[26] Abdel-Hameid, N.A.H. (2011) Effect of Starving and Feeding on Some Haematological and Physiological Responses of the Nile Catfish, Clarias gariepinus Exposed to Copper at Extreme Seasons. Fish Physiology and Biochemistry, 37, 875-884.

https://doi.org/10.1007/s10695-011-9485-0

[27] Okocha, R.C. and Adedeji, O.B. (2011) Overview of Cadmium Toxicity in Fish. Journal of Applied Sciences Research, 7, 1195-1207.

[28] Sun, Y., Li, Y., An, J., Liu, Z. and Chen, Q. (2019) Antioxidative and Inflammatory Responses in Spleen and Head Kidney of Yellow Catfish (Pelteobagrus fulvidraco) Induced by Waterborne Cadmium Exposure. Turkish Journal of Fisheries and Aquatic Sciences, 20, 87-96.

[29] Jalaludeen, M.D., Arunachalam, M., Raja, M., Nandagopal, S., Sundar, S. and Palanimuthu, D. (2012) Histology of the Gill, Liver and Kidney Tissues of the Fresh Water Fish Tilapia Mossambica Exposed to Cadmium Sulphate. International Journal of Advanced Biotechnology and Research, 2, 572-578.

[30] Suchana, S.A., Ahmed, M.S., Islam, S.M., Rahman, M.L., Rohani, M.F., Ferdusi, T., Ahmmad, A.S., Fatema, M.K., Badruzzaman, M. and Shahjahan, M. (2020) Chromium Exposure Causes Structural Aberrations of Erythrocytes, Gills, Liver, Kidney, and Genetic Damage in Striped Catfish Pangasianodon hypophthalmus. Biological Trace Element Research, 199, 3869-3885.

https://doi.org/10.1007/s12011-020-02490-4 